\title{
Sustainability in Ecovillages - A Reconceptualization
}

\author{
Susanna Waerther \\ Abertay University, United Kingdom
}

\begin{abstract}
:
This paper identifies and explores factors affecting sustainability and their interrelationships within the context of ecovillages. Through critical analysis of the theoretical concepts of sustainability and ecovillages as intentional communities, as well as their practical exploration through a multiple case study, a contextualised reconceptualization of sustainability is developed. The conceptual framework proposed in this paper depicts sustainability as a dynamic, context-dependent concept consisting of a variety of interdependent factors.
\end{abstract}

The ecovillages looked at are held together by shared principles, which act as unifying themes. They translate the community characteristics (lifestyle, commitment, understanding) into community activities. These activities can be organised into different dimensions (environmental friendliness, economic alternatives, social network, organisation), all including the element of self-sufficiency to a greater or lesser extent. Sustainability has different levels (personal, community, global); ecovillages are connected to society and network with other communities, creating a link between the internal and external factors. Regular review processes address the dynamics of the factors; this self-reflexivity helps to keep the communities dynamic, and through the interrelationships of the factors can lead to enhanced sustainability.

With a holistic approach to a reconceptualisation in a practical context, the conceptual model proposed in this paper facilitates a deeper understanding of the concept. Drawing on findings from a multiple case study conducted in Scotland and Germany, through in-depth interviews with inhabitants of ecovillages involved in the organisation of their communities, it offers a guideline for understanding sustainability in ecovillages and can serve as inspiration to rethink conceptualisations of sustainability to date.

Paper type: Research paper

Keywords: Sustainability, Ecovillages, Sustainable Development, Community, Intentional Communities 


\section{Introduction}

The contradiction of the claimed necessity for continuous growth in a world with finite resources, the irreversible impacts on the ecosystem as well as continuous change in society have led to an increased awareness of the consequences of our actions (Yanarella and Levine 2011; Bates 2005; Taylor 2003). The aggravation of these changes through the globalization of society and economy (Levitt 1983) resulting in increased instability of the political, economic, social and ecological environment - has provoked the sustainability debate and has reinforced it (Yanarella and Levine 2011). This debate is gaining increasing attention ever since the World Commission on Environment and Development coined a definition and programme for 'sustainable development', seeking to reconcile the trends of economic growth and declining resources (WCED 1987; Bell and Morse 1999). The sustainability debate is increasingly relevant, as the pace of change continues to step up. However, it remains a vague and contested concept without any universally accepted definition or meaning (Connolly cited by Yanarella and Levine 2011).

Despite the acknowledgement of the challenge of sustainability on a higher political level, the focus tends to be on resolving issues with a short term focus, which often restrains sustainability, leading to a 'sustainability schizophrenia'. The task of facilitating sustainability has been delegated to the local level, and there it is mainly local grass root organizations that forward it (Yanarella and Levine 2011). Ecovillages can be seen as such organizations: they address the challenges modern society faces using alternative approaches that tend to be more sustainable (Dobson 2007). An insight into what keeps these communities together - or what factors affect their sustainability - and how these factors are interconnected, can be used as inspiration and role model for different contexts, and change the way sustainability is looked at from an intercontextual point of view.

With a top-down approach to defining and implementing, and bottom-up forwarding of possible solutions, the sustainability debate shows the incoherence of the concept (Bell and Morse 1999; Yanarella and Levine 2011). This is reflected by research to date, which has been too narrow (Dobson 2007), mainly focusing on defining without context, or implementing predetermined concepts, aiming at measuring sustainability rather than understanding it. Increased exposure to environmental problems did not necessarily lead to a better understanding of their causes, consequences or solutions (Dobson 2007). What is needed is a holistic reconceptualization of sustainability (Imran et al., 2014) that reflects the bottom-up approach by incorporating the practical dimension, without losing sight of the theoretical knowledge that has been created as yet, avoiding a resource intensive 'reinvention of the wheel' (Mather 2014). It is essential to be aware of realistic and available routes to sustainability, and ideas about a sustainable society that help to bring these about (Dobson 2007).

This paper addresses the need for such a holistic view by examining the concept of sustainability in the context of ecovillages, identifying and exploring the key factors that affect sustainability in ecovillages. Presenting the outcomes of a multiple case study conducted among ecovillages in Scotland and Germany, the paper proposes a 
conceptual model with a bottom up approach that facilitates a deeper understanding of the concept, as well as indicating key factors to be addressed for enhancing sustainability.

The paper is organized in six sections. After the introduction, a critical analysis of the concepts - sustainability and ecovillages - looking at key aspects and approaches, points out their vagueness and dynamics. Both are perceived in different ways and lack a final definition, which indicates their contest. The third section briefly outlines the methodology of the study that was conducted prior to the writing of this paper. The paper then presents the outcomes of this study, proposing a conceptual framework that visualizes the key factors affecting sustainability in ecovillages indicating that shared principles and commitment are the main unifying elements. It then continues to explain how sustainability in ecovillages can be enhanced using this framework, emphasising the importance of self-reflexivity in the communities. The sixth and last section concludes with the implications of the study, pointing out the importance of the contextualization of the concept of sustainability and the need to address its dynamics.

Both Scotland and Germany play a decisive role in the ecovillage movement, which was initiated in Scotland, with German communities being highly involved in the founding and developing process (Jackson 2004; GEN 2013). Both countries feature ecovillages that serve as an inspiration for the founding of new intentional communities, which grow to be more experienced and stabilised over the years (Stengel 2005; Bang 2005; GEN 2013). The amount of ecovillages continues to increase, especially in Germany (Stengel 2005), and these two countries are considered a suitable setting for the case study.

The terms sustainability and sustainable development are used interchangeably, as has been done in previous literature (Bell and Morse 1999). An ecovillage in this paper is an intentional community that attempts to continuously improve its approach to support healthy human development and decrease its impact on the environment by considering the sustainability of its actions.

\section{The concept of sustainability - relevant but contested}

Ever since the World Commission on Environment and Development coined the term 'sustainable development' to determine the concept of continuous growth in a world with finite resources, the concept of sustainability attracted worldwide attention (Yanarella and Levine 2011; Imran et al., 2014). Since then the sustainability debate did not cease to be of major concern to research, economy and politics. The general growth-resource paradox has been discovered long before the Earth Summit in Rio by researchers such as Malthus (1798). The Limits to Growth report conducted for the Club of Rome in the 1970s expanded on this concept and pointed out the consequences of unchecked growth; stating that besides the tangible physical needs, there are social needs that have to be addressed to sustain world economic and population growth (Meadows et al., 1972). Although this report has encouraged a political debate and movement that have addressed the outlined environmental 
concerns, it is only with the apparent irreversible impacts of an increasingly industrialised and globalised world that sustainability is of central concern (Dobson 2007).

There have been various attempts at defining and measuring sustainability - with the triple bottom line dividing sustainability into social, economic and ecological dimensions (Yanarella and Levine 2011) and sustainability indicators such as the ecological footprint (Bell and Morse 1999). The vagueness of these approaches and the lack of a final universal definition confirm the contest of the concept (Dobson 2007; Connolly cited by Yanarella and Levine 2011). The definition of 'sustainable development' given by the WCED as '[...] development that meets the needs of the present without compromising the ability of future generations to meet their own needs" (WCED 1987, p. 43) acknowledges the concepts of needs and limitations and their implications to economic and social development (WCED 1987; Meadows et al., 1972). It has been criticised for being too anthropocentric (Imran et al., 2014), and it has been questioned whether sustainable development can lead to sustainability (Yanarella and Levine 2011), but as it is the most agreed upon definition in politics and research (Imran 2014; MacGillivray 1998) as well as community networks (GEN 2013), it can serve as an approximation to provide an initial understanding. It led to the development of Agenda 21, a framework for sustainability that can be divided into social, economic, ecological and institutional factors (United Nations 1993; Bell and Morse 1999). Many of its parameters, elements and factors are kept vague (Webster 1998; Bell and Morse 1999), but when comparing research to date, there is a notable compliance to this approach.

The sustainability schizophrenia - acknowledgement of the relevance of sustainability on the higher political levels, yet a short term focus of resolving issues that often hamper sustainability efforts - leaves the task of forwarding sustainability with individuals and local, often so called grass root organizations (Yanarella and Levine 2011) that can address the issues more effectively (Brenton 1994). As the nature of the consequences of growth is transnational, international agreements and incentives are never obsolete. There is a need to work with local incentives rather than across them (Brenton 1994), therefore the approach to the concept of sustainability has to be a practical, bottom-up approach, meeting the top down approach outlined in the Rio Declaration.

More recent events like the conference Rio+20 and the UN decade for sustainable development confirm the relevance of the concept and the ongoing debate about it (United Nations 2012; Yanarella and Levine 2011). The sustainability schizophrenia leaves the task of progressing sustainability with local grass root organizations (Yanarella and Levine 2011), and it is important to understand these organizations.

\section{Ecovillages - new approaches to old social structures and a potential alternative}

Ecovillages are predominantly intentional communities; sharing life time, visions and values on a voluntary basis in an informal cooperation of everyday life (Stengel 2005). As such they are organizations that - consisting of individuals - are set within

International Journal of Management and Applied Research, 2014, Vol. 1, No. 1 
society, and face the same challenges and trends. Ecovillages themselves are difficult to define, as they are communities that have "different meanings in different contexts and to different people" (Warburton 1998, p. 17). The definitions vary; with some including high ecological standards (Jackson 2004), while others include a particular scale (GEN 2013). For the purpose of this paper, ecovillages are defined as intentional communities that attempt to continuously improve their approach to support healthy human development and decrease their impact on the environment by considering the sustainability of their actions. This reflects the view of ecovillages as learning and developing communities rather than fixed institutions, as well as the importance of sustainability as element of ecovillages (GEN 2013; Bang 2005).

The main focus in ecovillages is on social aspects, as they try to combine individual and community life (Stengel 2005). As the term indicates, they have a strong ecological focus as well; trying, for instance, to grow their own organic food in the community bio-region, and support localised systems of economic and ecological management (GEN 2013). With the willingness to experiment, ecovillages promote an alternative lifestyle that tends to be more ecologically and economically sustainable and often self-sufficient to a great extent (Bang 2005; GEN 2013). To better understand ecovillages, it is important to grasp the concept of intentional communities.

The continuous change of modern society - accelerated through globalization - has led to progressed segregation, separation, exclusion (Bauman 1998) and the breaking up of old structures, resulting in an increasing need for belonging and security (Bauman 2001; Blackshaw 2012). Together with the loss of the "traditional communities' that used to meet these needs without a sufficient substitute, this led to the creation of new kinds of communities - intentional communities (Bauman 2001; Delanty 2010). 'Community' itself has become an increasingly vague and romanticised concept (Blackshaw 2012); a community can broadly be defined as a group that shares something or whose members agree on certain characteristics, behaviour or interests (Stengel 2005).

Communities create security and a sense of belonging; they provide a form of support and stability through networks, reciprocity and trust (Bauman 2001; Taylor 2003). Intentional communities are often mutual, sharing trust and knowledge through a shared purpose, pooling economic risk and offering opportunities for social and politic interaction (Leadbeater and Christie cited by Taylor 2003). However, the concept of community has been subject to criticism.

Where 'old communities' had a natural, shared understanding, intentional communities have to continuously agree on shared, unifying elements in a 'rolling contract' (Bauman 2001, p.12) that reflects the differing interests within a community (Taylor 2003). This indicates the frailty of these consciously formed communities, as they face the danger of dissolving as soon as a rolling contract can no longer be reestablished (Bauman 2001). Intentional communities are often perceived as exclusive groups, distinguishing between 'us' and 'them' (Bauman 2001). They can become fixed, hierarchical and oppressive (Taylor 2003).

International Journal of Management and Applied Research, 2014, Vol. 1, No. 1 
As part of the same environment, ecovillages can be seen as alternatives to the 'standard lifestyle' of modern society, with environmental and social concerns as central elements (Bang 2005). The concept of ecovillages is developing, and it has drawbacks that need to be addressed. However, ecovillages as alternatives to existing norms and practices show the possibility of a different and more sustainable life (Dobson 2007). They can be seen as model projects for sustainable development (GEN 2013), addressing the consequences of unchecked industrial development and the challenges faced by modern society in an alternative way (Bates 2003; Dobson 2007).

\section{Exploring sustainability in ecovillages - two complex, connected concepts}

With increasing political and economic instability, social isolation and the danger of resource scarcity (where not already present), there is a need for alternatives that are more sustainable (Yanarella and Levine 2011; Bell and Morse 1999). Intentional communities, and ecovillages in particular, can be seen as such alternatives: model settlements that promote an inspiration on how to approach the challenges faced by modern society in a different way. As such they offer a suitable context for a more practically oriented, bottom-up reconceptualization of sustainability. Besides the rationalization of sustainability in ecovillages, the question of how it can be secured and enhanced is addressed in this paper.

It has been argued that to promote change in communities - and an enhancement of sustainability arguably involves change - the people whose actions have an impact on the community have to relate to the things that are going to change (Lawrence 1998; Bell and Morse 1999). Especially in communities it is important to have a clear idea of how to operate in a sustainable way (Dobson 2007). This can be achieved by involvement and engagement of the individual members of the community, their ownership of the processes and personal commitment (Webster 1998). A deeper understanding of the concept of sustainability can serve as a foundation for common action, and as such promotes change (Lawrence 1998).

\section{Methodology of the study}

The study that serves as basis for this paper was set up as a multiple case study, including data from six ecovillages that were founded between 15 and 50 years ago and are equally distributed in Scotland and Germany. Five in-depth interviews were conducted with five voluntary respondents who live and work in ecovillages and are involved in the organisation of their community. Drawing on 'first-hand-knowledge', this approach allowed for a practical, bottom-up understanding of the concept. Through the multiple case study design a conceptual model could be developed that integrates both practical and theoretical knowledge with an interpretive research philosophy.

The exploratory study followed a mainly critical hermeneutic approach. It analyses the research phenomena acknowledging subjective values and pre-suppositions of both researcher and respondents, and avoides bias of opinion through the multiple 
case study research design (Schwandt 1997). It is sceptical of claims to finite truth; interpreted meaning is seen as provisional assumption continuously made and revised as a result of complex situations (Rickman cited by Burrell and Morgan 1979). Through aiming at emancipation from taken-for-granted circumstances, this approach bears the potential for social change (Schwandt 1997).

Data was analysed with thematic analysis, open as well as axial coding, which allowed the development of patterns both emerging from data as well as predetermined from theory (Schwandt 1997). To explore the concept of sustainability in a suitable practical context, the selected cases are ecovillages according to the definition given in the first section of the article.

The selected cases should not be seen as a representative group for ecovillages, as their geographical scope is limited to Germany and Scotland. With five research participants that act as representatives for their communities, the case study qualitatively explores the research phenomena.

\section{Reconceptualising sustainability in ecovillages}

The findings of the study indicate that sustainability of ecovillages is dependent on various interconnected factors. These have been summarised in the conceptual model in figure 1. The key factor that keeps a community together are shared principles. As the basis for community life, these are the unifying themes the community members commit to, despite diversity in individual values and priorities. These shared principles often reflect the experimental character of the ecovillages:

"[...] our aim is to change something within the system in which we live at the moment, to show new ways. And at the same time to build an alternative that can support if the system [...] breaks down."

"But even though the opinions might differ [...] we're all pulling together and we are living together [...] as sustainable as I can imagine it to be."

The shared principles form the basis for community life; as the agreed upon elements members commit to, that are an angling point for communication and understanding, and have implications for the lifestyle. They are formed and influenced by the understanding, commitment and lifestyle of the members, and can be seen as 'common interest' that keeps the community together (Bauman 2001; Taylor 2003). In the words of a respondent:

"[...] we have a common ground we live by, [...] agreements we all agree to for long. [...] it's part of our life basically."

This especially is the case in the 'pioneering phase' of the community, when the commitment is high to engage in an alternative lifestyle, with a shared understanding of what the ecovillage should be (and therefore, what it should not be). This phase requires a considerable amount of energy and willingness of all members, often referred to as 'pioneering spirit'. The decision to become a member is taken 
voluntarily and consciously, with the membership being something desirable (Taylor 2003; Bauman 2001):

" [...] there is a pioneering phase, where initially there is a lot of deprivation involved, to build something like this. It simply takes a huge amount of energy on different levels to build something like this. And then there's a phase where this has some kind of normality, where it is a little bit like a made nest, where people come to and do not have a pioneering feeling which is that strong."

The loss of pioneering spirit is a critical development encountered in communities, often together with a process of becoming 'absorbed in society' (Pepper cited by Dobson 2007). This highlights the importance of keeping the momentum of the pioneering phase, which is achieved through reaffirming the shared principles with a consensus based 'rolling contract' (Bauman 2001). Commitment, understanding and lifestyle - in their reciprocal relationship with the shared principles - can be summarized as community characteristics, constituting the character of the ecovillage.

Figure 1. The proposed conceptual model for sustainability in ecovillages.

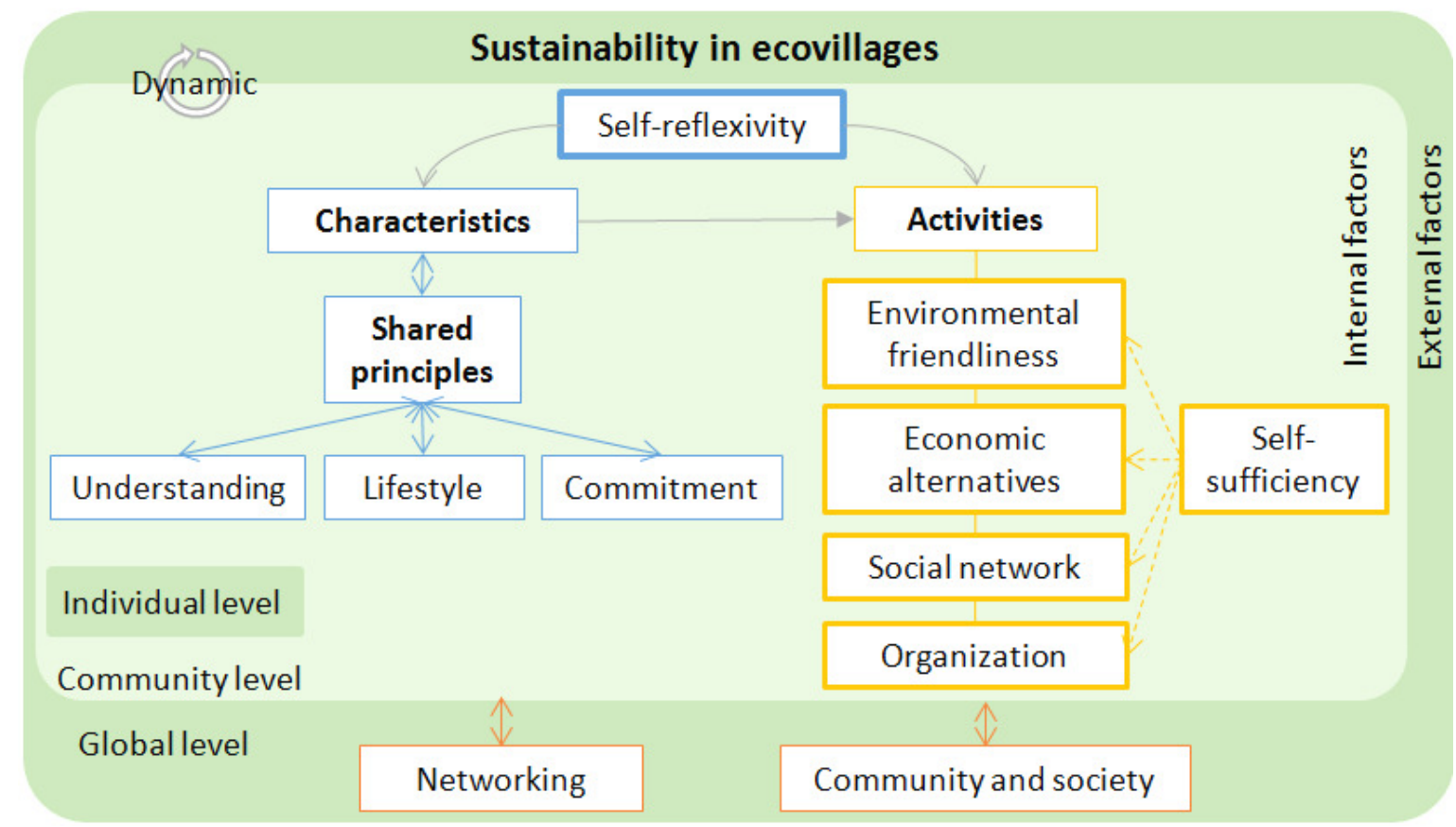

The community characteristics are discernible but invisible, concentrated in the shared principles that transfer the factors from the individual to the community level. The shared principles also provide a foundation for and determine the approach taken to the community activities. These activities reflect community life in its observable and measurable form. As the term suggests, ecovillages have a focus on the ecological aspects, aiming to be environmentally friendly (Bang 2005; Bates 2003). This includes for instance reduction of the ecological footprint, and ensuring local and seasonal supply. It is often the desire of the members for their ecovillage to be 
"[a] community of people that live together and try to live as ecologically as possible $[\ldots]$ ”

As community, the social aspects are equally if not more important - there is a notable shift of focus towards the social aspect - with mutual support and communication as two key elements building a strong social network within the community.

"[...] there is more and more isolation [...]; community life is one possibility to counteract that. And in that line of thought leads to sustainability on the social level $[\ldots]$ ”

The economic aspects are important by necessity, as the ecovillages are still 'part of the system' and 'have to pay the bills':

"[...] the individuals and the community need income to survive in this world. Even though the needs are not as high as if you live on your own somewhere in the city. Still, the economic pressures are there."

The communities react to this requirement in a way that is coherent with their shared principles. They use alternative approaches, such as community supported agriculture or a shared economy.

Although some communities aim at reducing hierarchy, all ecovillages feature structured decision making processes, as well as often complex organizational structures, with councils and clear responsibilities. This confirms the view that the contest of a concept - in this case community - becomes evident in politics (Connolly cited by Yanarella and Levine 2011). Nevertheless the role of the individual in the community - regarding all aspects, but in its consequences particularly in decision making processes - is emphasized.

"The one thing is how our community institution decides, like as association or collective, and the other thing is the private level."

Environmental friendliness, social network, economic alternatives and structured organization - summarised as community activities - confirm the framework of sustainable development derived from the Earth Summit in Rio 1992; which suggests that sustainability can be divided mainly into social, economic and ecological, but also institutional factors (United Nations 1993; Bell and Morse 1999). These different aspects are interdependent, which leads to inevitable trade-offs, but also positively reinforcing effects:

"[...] there's a strong relation, in short: If I am well off on the social level, then I don't need that many products or means as compensation, so to speak.”

“ [...] it's all about how can we sustain ourselves as well. As way to care for the environment and put lots of work in, but if we are suffering and attacked because we don't get what we need, then it's also not sustainable [...] on a personal level, and then on a community level, and then also on a global level $[\ldots]$ ” 
This indicates not only that the different dimensions of community life influence each other, but also that there are different levels of sustainability that have to be balanced as well.

The degree of self-sufficiency in an ecovillage determines how independent the community is on the external environment. It is an aspect of every community activity; however, it tends to be more prominent in the economic and partly ecological dimension - with increased independence through community owned resources and systems, as well as the application of the 'cradle to cradle' idea when it comes to, for instance, waste management. This increases the awareness of the needs and limitations that are essential concepts of sustainability (WCED 1987):

"[...] our perception of self-sufficiency [...] has an aspect of sustainability [...] to have an awareness of how much [...] is available and consumed."

Self-sufficiency has to be balanced in order to contribute in a positive way to sustainability (Paech 2010). An ecovillage has to acknowledge the interdependences that exist in a community consisting of individuals; situated within the environment it depends upon for providing resources (Hatch 1997). As has been said before, the ecovillages are still part of the system, therefore they inevitably face these interdependences:

"[...] we don't see ourselves as exit from society, we are connected with it in various ways."

"Especially in the summertime we have guests from all over the world joining our community and joining our lifestyle, so there's a close link going out to society again."

Ecovillages are in a reciprocal relationship with their external environment. This relationship has both positive and negative effects. The communities are examples for alternative approaches to issues society faces today; they inspire people to change their lifestyles to become, for instance, more environmentally friendly. The idea is

“[...] to pass on ideas for people who are interested. About how can I lead a more ecological live [...] people come here and are interested, and take things home with them, and say: "okay, I want to change this and that'."

Some ecovillages provide educational and retreat functions to guests and visitors, engage in a dialogue with institutions and educational activities, and are even acknowledged on the higher political level as examples for sustainable development. In turn, guests and visitors provide the ecovillages with an income. Through this (regulated) exposure, the communities are frequently questioned in their approaches and have to continuously define their characteristics and activities.

The ecovillages in the study tend to operate inside the prevailing cultures rather than outside them, thus facing the threat of becoming absorbed into conventional society, which most of them oppose in one way or the other (Pepper cited by Dobson 2007).

International Journal of Management and Applied Research, 2014, Vol. 1, No. 1 
Despite this openness to society, there is often little understanding on a local political level, and in the direct neighbourhood.

"So we encounter difficulties on a direct local level, that some things are not shared of how we live here."

Another external connection is the networking with other communities, especially ecovillages. Although not always a priority, networking is seen as useful tool for sharing knowledge, and to engage in shared activities and further initiatives:

“[...] we [can] ask someone else to help us, to facilitate the process. [...] we can reach out for help [...]”

Community networks form around unifying themes, from geographical proximity to common interests, like the ecovillage movement. They require resources, and diverging views of diverse communities often complicate the efforts taken - the networks face similar problems with these unifying themes - or shared principles - as the communities do on an internal level.

To ensure the continued consent within the communities, the ecovillages feature review processes that help to reaffirm their shared principles or unifying themes, linking back to the rolling contract (Bauman 2001). These review processes range from informal community meetings, where arising issues are addressed at once, to formal convocations dedicated to reflection. A respondent explains how the process looks like in his community:

"[...] we have a rotational intensive time [...] to see, [...] what can we change and what are possibilities for future change."

In most cases the topics addressed in the reviews mainly refer to the observable community activities. Where community characteristics are reviewed, members reflect on their understanding of and commitment to the shared principles.

Respondents emphasized the importance of the differences between the individual members, particularly in their understanding. The study shows that there is no final definition of sustainability in ecovillages, even though the members of ecovillages agree on shared principles, and tend to be more aware of the concept in general.

"Indeed, the term 'sustainability" is not really used in everyday life. [...] it appears only rarely, because it is more... integrated implicitly.”

This confirms the contest of a concept that is shared widely but imperfectly (Yanarella and Levine 2011). Sustainability tends to be understood individually and implicitly. Each ecovillage has an individual approach to the different factors, showing the importance of contextualization of the sustainability concept. 


\section{Enhancing sustainability - key factors to be addressed}

The findings suggest that it is more important to raise general awareness about sustainability in order to have a common ground for community action rather than having fixed guidelines. What is required is a much broader, holistic conceptualisation of sustainability (Imran et al., 2014). The reconceptualization of sustainability proposed in this paper facilitates change towards enhanced sustainability through deepening of the understanding. This enables the community members to effectively address problems by increased action taking (Yanarella and Levine 2011; Lawrence 1998).

The loss of pioneering spirit reflects a decrease of organizational commitment over time, and potentially results in negative attitudes toward the ecovillage, also known as organisational cynicism (Dean et al., 1998). The key to enhanced sustainability are dynamic shared principles. Referred to as common interest they work as 'community glue', keeping the community together despite differing individual interests (Taylor 2003). Together with individual commitment they are a condition for sustainabilityrelated action (Yanarella and Levine 2011). It is therefore crucial for the sustainability of ecovillages to keep the commitment dynamic through self-reflexivity and at the same time to ensure the stability of the community by reinforcing shared principles. It is a way of assessing the commitment and monitor changes that inevitably affect the community as well as react to them. This self-reflexivity has to be participative and integrating the community members (Lawrence 1998; Bell and Morse 1999), so the shared principles can be adapted whenever this is needed. This means that they reflect the community characteristics not only in the pioneering phase, but throughout the whole existence of the community.

Other than increasing the adaptability and flexibility; a continued reaffirmation of unifying themes in the form of a rolling contract increases commitment and understanding among the community members (Bauman 2001). Through practical implementation of the shared principles, the effect on commitment and understanding is increased (Lawrence 1998), as they not only represent, affect and partly determine the characteristics of the community; but as a basis for shared action also determine the approach to community activities. This in turn enhances the willingness to act, and the potential for positive change, which can result in increased sustainability through alignment of the internal and external factors.

Networking with other communities can help to reinforce internal efforts, as it facilitates sustainability through provision of support without creating unnecessary dependences. Being part of a community network can enhance the learning capabilities through exchange of knowledge, and therefore avoid repeated mistakes and doubled research efforts (Mather 2014; Bang 2005). An awareness of the relation to society - and a conscious decision regarding the positioning inside or outside the prevailing culture - helps to clarify and support the intent of the ecovillage as being an inspiring alternative or a means for radical change (Dobson 2007).

International Journal of Management and Applied Research, 2014, Vol. 1, No. 1 


\section{Conclusion}

Sustainability remains a complex and contested concept (Yanarella and Levine 2011). It is confirmed in this paper that it is understood individually and implicitly rather than bearing potential for a shared, universal understanding. It therefore has to be explored in a practical context to create a foundation for common action. Sustainability is not only context-dependent, it is also a highly dynamic concept; requiring a dynamic approach that reflects changes and is readily adaptable, but at the same time stabilising. A conceptualisation of sustainability has to aim for a balanced view on the different levels of individual, community and society; a top-down and bottom up approach, as well as the different changing internal and external elements that affect sustainability.

Integration of mutual interplay and trade-offs in models of sustainability is crucial for an improved understanding of the concept (Greeuw et al., 2000), which can only be delivered by a holistic approach. It is the ambition of this paper to reflect this in the proposed conceptual model for sustainability in ecovillages. Like any conceptual model, it should not be seen as static or as a general standard, but a reflection of the data derived from the study, and an inspirational guideline that has to be contextualized. As Yanarella and Levine state (2011): sustainable balance-seeking processes cannot be static, as human life and social activities continuously introduce changes that must be balanced with the larger environment. This environment has a dynamic on its own, which only increases with progressing globalisation (Levitt 1983).

This paper can be seen as a foundational piece of work, encouraging further research on the ever relevant subject of sustainability in all its aspects. It hopes to encourage interdisciplinary research that combines theoretical and practical knowledge. Another important question that has only been touched upon superficially in this paper is the attitude to and support of ecovillages mainly on a local level, and the relation to society in general. It is worth exploring the concept with a similar approach in a different context to support or contradict the outcomes of the study, and to further improve the understanding of sustainability.

\section{References}

1. Bang J.M. (2005), Ecovillages - A practical guide to sustainable communities, Edinburgh: Floris Books.

2. Bates A. (2003), Ecovillage roots (and branches) - When, where and how we re-invented this ancient ecovillage concept, available at: http://ena.ecovillage.org/index.php?option=com_content \&view=article \&id=71 \%3Aecovillage-roots-and-branches-when-where-and-how-we-re-invented- 
this-ancient-village-concept\&catid=35\%3Aarticles\&Itemid=71\&lang=en (accessed on 23 November 2013).

3. Bauman Z. (1998), Globalization - The human consequences, Oxford: Polity Press.

4. Bauman Z. (2001), Community - Seeking safety in an insecure world, Oxford: Polity Press, Cambridge in association with Blackwell Publishers Ltd.

5. Bell S, Morse S. (1999), Sustainability indicators - Measuring the immeasurable?, London: Earthscan Publications Ltd.

6. Blackshaw T. (2010), Key concepts in community studies, London: SAGE Publications Ltd.

7. Brenton T. (1994), The greening of Macchiavelli - The evolution of international environmental politics, London: Earthscan Publications Ltd.

8. Dean J.W. Jr, Brandes P., Dharwadkar R. (1998), "Organizational cynicism", In: The Academy of Management Review, Vol. 23, Nr. 4, pp. 341-352.

9. Delanty G. (2010), Community, $2^{\text {nd }}$ edition, Oxon: Routledge.

10. Dobson A. (2007), Green Political Thought, $4^{\text {th }}$ edition, Oxon: Routledge.

11. Greeuw S.C.H., van Asselt M.B.A., Grosskurth J., Storms C.A.M.H., RijkensKlomp N., Rothman D.S., Rotmans J. (2000), Cloudy crystal balls - An assessment of recent European and global scenario studies and models, Environmental Issues Series, Copenhagen: European Environment Agency.

12. Hatch M.J. (1997), Organization Theory - Modern, symbolic, and postmodern perspectives, Oxford: Oxford University Press.

13. Imran S., Alam K., Beaumont N. (2014), "Reinterpreting the Definition of Sustainable Development for a More Ecocentric Reorientation”, Sustainable Development, Vol. 22, No. 2, pp. 134-144. https://doi.org/10.1002/sd.537

14. Jackson H. (2004), What is an ecovillage?, available at: http://www.gaia.org/mediafiles/gaia/resources/HJackson_whatIsEv.pdf (accessed on 26 October 2013).

15. Lawrence J.G. (1998), "Getting the future that you want: The role of sustainability indicators", In: Warburton, D. (Ed). Community and sustainable development - Participation in the future, London: Earthscan Publications Ltd. in association with World Wide Fund for Nature (WWF-UK), pp. 68 - 80.

16. Levitt T. (1983), “The globalization of markets”, In: DeWit B, Meyer R (Eds). Strategy: Process, content, context - an international perspective, $3^{\text {rd }}$ edition, London: Thomson Learning. 
17. MacGillivray A. (1998), "Turning the sustainability Corner: How to indicate right”, In: Warburton, D. (Ed). Community and sustainable development Participation in the future, London: Earthscan Publications Ltd. in association with World Wide Fund for Nature (WWF-UK), pp. 81 - 95.

18. Malthus T.R. (1798), First essay on Population, London: Macmillan and Company Ltd.

19. Mather J. (2014), "Overcoming the knowledge gap", The environmentalist, No. 4, available at: http://www.environmentalistonline.com/article/2014-0406/overcoming-the-knowledge-gap (accessed at 21 May 2014).

20. Meadows D.H., Meadows D.L., Randers J., Behrens III W.W. (1972), The limits to Growth - A report for the Club of Rome's project on the predicament of mankind, London: Pan Books Ltd.

21. Paech N. (2010), "Effizienz, Konsistenz, Suffizienz - Wie wird Wachstum nachhaltig?", Presentation at Evangelische Akademie Loccum Conference, Politik in der Wachstumsfalle " (Politics in the growth trap), $2^{\text {nd }}$ July, 2010, available at: http://www.loccum.de/material/staat/wachstum/paech.pdf (accessed at 7 April 2014).

22. Schwandt T.A. (1997), Qualitative inquiry - A dictionary of terms, Thousand Oaks, CA: Sage Publications Inc.

23. Stengel M. (2005), "Was ist Gemeinschaft? - Definitionssuche und Überblick", In: Stengel, M (Ed). (2005), Eurotopia 2005 - Gemeinschaften und Ökodörfer in Europa, Poppau: Einfach Gut Leben e.V., pp. 10 - 15.

24. Taylor M. (1998), "Achieving community participation: The experience of resident involvement in urban regeneration in the UK", In: Warburton, D. (Ed). Community and sustainable development - Participation in the future, London: Earthscan Publications Ltd. in association with World Wide Fund for Nature (WWF-UK), pp.163 - 181.

25. Taylor M. (2003), Public policy in the community, Hampshire: Palgrave Macmillan.

26. The Global Ecovillage Network Website (2013), available at: http://gen.ecovillage.org/ (accessed on 12 March 2014).

27. United Nations (1993), The report of the United Nations conference on environment and development - Volume 1: Resolutions adapted by the conference, New York: United Nations. 
28. United Nations (2012), Report of the United Nations Conference on Sustainable Development - Rio de Janeiro, Brazil, 20-22 June 2012, available at:

http://www.uncsd2012.org/content/documents/814UNCSD\%20REPORT\%20f inal\%20revs.pdf (accessed on 9 July 2014).

29. Webster K.G. (1998), "Developing Community Local Agenda 21s", In: Warburton, D. (Ed). Community and sustainable development Participation in the future, London: Earthscan Publications Ltd. in association with World Wide Fund for Nature (WWF-UK), pp. 182 - 197.

30. Warburton D. (1998), "A passionate dialogue: Community and sustainable development”, In: Warburton, D. (Ed). Community and sustainable development - Participation in the future, London: Earthscan Publications Ltd. in association with World Wide Fund for Nature (WWF-UK), pp. 1 - 39.

31. World Commission on Environment and Development (WCED) (1987), Our common future, Oxford: Oxford University Press.

32. Yanarella E.J., Levine R.S. (2011), The city as fulcrum for sustainability, London: Anthem Press. 